\title{
A utility-tailored methodology for integrated asset management of urban water infrastructure
}

\author{
Helena Alegre*, Sérgio T. Coelho*, Dídia I.C. Covas**, Maria do Céu Almeida*, Adriana Cardoso* \\ * LNEC - National Civil Engineering Laboratory, Av. Brasil, 101, 1700-066 Lisboa, Portugal \\ ** Instituto Superior Técnico (IST), Av. Rovisco Pais, 1, 1049-001 Lisboa, Portugal
}

\begin{abstract}
This paper presents the integrated methodology for infrastructure asset management (IAM) developed in AWARE-P, an R\&D project aimed at producing adequate and effective support tools for assisting urban water utilities in decision making and rehabilitation planning (www.aware-p.org). The proposed methodology addresses all three planning and decisional levels (strategic, tactical and operational) and follows a PDCA-inspired cycle. The methodology assesses the water systems and any planning solutions along the cost, risk and performance dimensions, with a variety of standardised assessment methods and models proposed for each. It differs from existing approaches in the incorporation, into a single organised framework, of the entire IAM process with an integrated, long-term vision of the urban water network - looking at the infrastructure as a system, and not as a mere sum of individual assets. The paper describes the approach and illustrates its application with reference to the several business cases already undertaken.
\end{abstract}

Keywords

Infrastructure asset management, water supply, wastewater, planning, rehabilitation, software.

\section{INTRODUCTION}

Successful infrastructure asset management (IAM) is essential in the long-term, sustainable compliance with performance requirements in urban water services. Effective decision-making requires a comprehensive approach that ensures the desired performance at an acceptable risk level, taking into consideration the costs of building, operating, maintaining and disposing of capital assets over their life cycles. Brown and Humphrey (2005) summarize it as 'the art of balancing performance, cost and risk in the long term'. The approach described here was developed under AWARE-P, an R\&D project aimed at producing effective tools for assisting urban water utilities in IAM decision-making (www.aware-p.org).

\section{METHODOLOGY}

The AWARE-P methodology, illustrated by the cube in Figure 1, incorporates the values generally respected in IAM practice (Hughes, 2002; INGENIUM and IPWEA, 2006; Saegrov, 2006; Sneesby, 2010). It approaches IAM as a management process, based on plan-do-check-act (PDCA) principles and requiring full alignment between the organisation's strategic objectives and targets, and the actual priorities and actions implemented. It expressly takes into account that a networked infrastructure cannot be dealt with in the same way as other collections of physical assets: it has a dominant system behaviour (i.e., the performance of individual assets is not independent from one another), and as a whole it does not have a finite life - it is not realistically replaceable in its entirety, only piecemeal.

The methodology is geared to the standardized assessment and comparison of intervention alternatives from the performance, cost and risk perspectives over the analysis horizon(s), given a set of previously-defined objectives and targets (Alegre et al., 2011; Marques et al., 2011; Cardoso et al., 2011). In a nutshell, the objective of the AWARE-P IAM approach is to assist water utilities in answering: who are we at present? what infrastructures do we own or operate? what service do we deliver? where do we want to be in the long term? how do we get there? 
At each level of management and planning - strategic, tactical and operational - a structured loop is proposed that comprises the 5 stages shown in Figure 2. While several elements of this process are commonly in place, often missing is a review mechanism - a way to measure compliance with set goals - as well as an effective alignment between the different levels. One area of particular concern is the setting up of clear-cut objectives, assessment criteria, metrics and targets, which are essential for unequivocal directions of action, as well as for accountability of results through timely review.

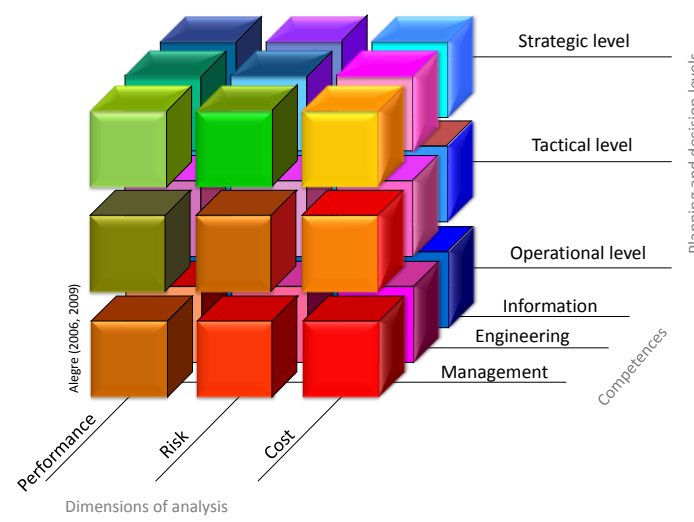

Figure 1 - The AWARE-P approach

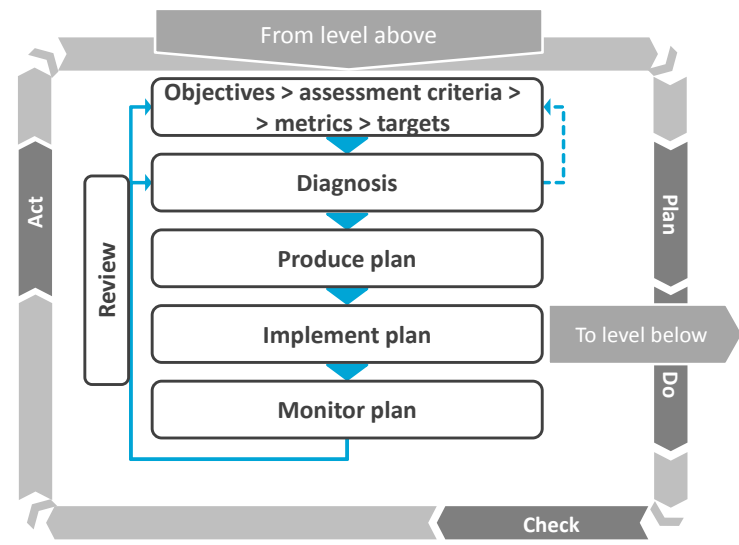

Figure 2 - The planning process (at each level)

Further to the organizational and management process, this approach sees IAM as a problem-driven process, guiding and assisting the utility decision makers in addressing the key infrastructurerelated issues by carrying out diagnoses, assessing and comparing alternative solution paths, and selecting the best performance, risk and cost trade-offs in view of the stated objectives.

\section{AWARE-P SOFTWARE}

The method is supported by an IAM planning software (Coelho and Vitorino, 2012; baseform.org) which makes available on an advanced technology platform the best tools for visualizing, diagnosing and evaluating any given water supply or wastewater system (Figure 3a), through a portfolio of performance, risk and cost models, at global and detailed levels. It enables the comparison of any number of alternative solutions, using standardized methods that facilitate informed decision-making. The software is web-based, open-source, and promotes data sharing and the integration of new modules through a plug-in architecture.

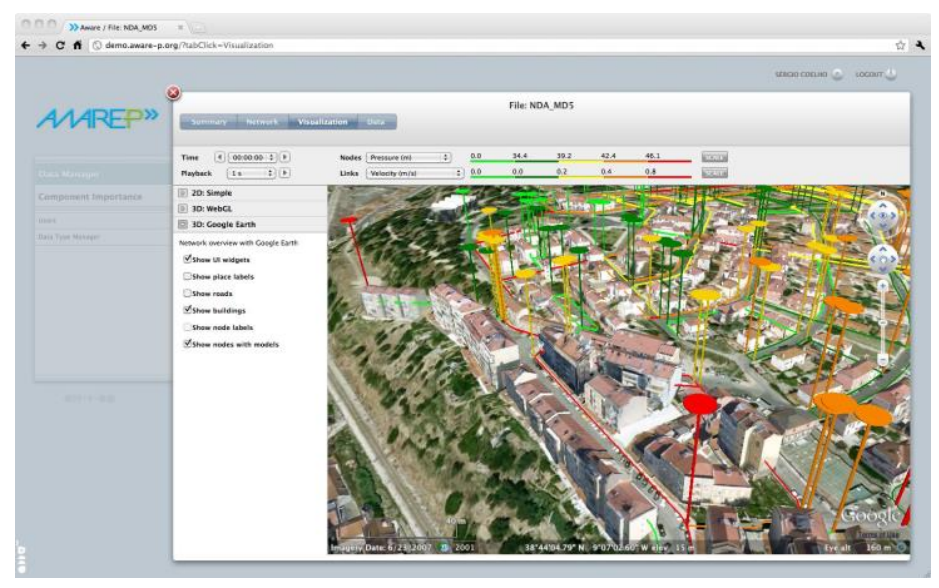

(a) Google Earth ${ }^{\circledR}$-based representation of network performance assessed from simulation model results

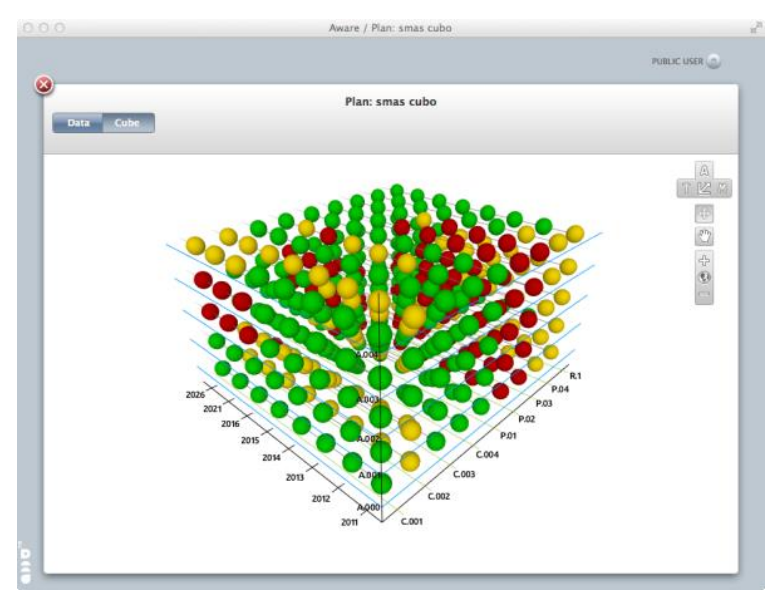

(b) Software planning tool: a 3D cube of results

Figure 3 - AWARE-P software platform

The AWARE-P software has essentially two main usage modes: (i) as a portfolio of assessmentoriented models and analysis tools that may be used (individually or in combination) in order to 
diagnose and gain sensitivity to a system; or (ii) supporting the AWARE-P IAM planning procedure through the definition of a planning framework (time horizon, metrics, alternatives) and by feeding the planning tool with metric values produced using the tools available.

PLAN is the tool that embodies the central planning framework of the AWARE-P infrastructure asset management programme, where planning alternatives or competing projects are measured up and compared through selected performance, risk and cost metrics, through interactive numerical and 2D/3D graphical information display. Figure $3 \mathrm{~b}$ shows a snapshot of the 3D view of results, in the form of a cube, whose dimensions are (i) time over the period of analysis, (ii) performance, cost and risk metrics and (iii) alternatives.

AWARE-P hosts a growing number of plug-in tools that are as effective at producing metrics that feed PLAN, as they are tailored for stand-alone usage, as fully-fledged analysis algorithms and models. The currently available range of metrics-producing tools include:

- PI - Performance Indicators, quantitative assessment of the efficiency or effectiveness of a system through the calculation of performance indicators based on state-of-the-art, standardized PI libraries as well as user-developed or customized ones.

- PX - Performance Indices, technical performance metrics based on the values of certain features or state variables of water supply and waste/stormwater networks. The indices measure performance concepts related to level-of-service, network effectiveness and efficiency.

- FAIL - using models such as Poisson and LEYP, prediction of future pipe or sewer failures for a given network, e.g. in the context of estimating risk or cost metrics, based on an organized failure history in the form of work orders and pipe data records.

- CIMP - calculates a component importance metric for each individual pipe in a network, based on the impact of its failure on nodal consumption. The measure is computed based on the network's hydraulic model, using full simulation capabilities.

- UNMET - calculates a service interruption risk metric expressed as the expected volume of unmet demand in a system over one year, given the expected number of outages for each pipe, the average downtime per pipe outage, and the component importance of each pipe, expressed in terms of unmet demand; system pipes are ranked accordingly.

- IVI - Infrastructure Value Index, representing the ageing degree of an infrastructure, calculated through the ratio between the current value and the replacement value of the infrastructure.

- NETWORK-EPANET - an efficient, Java-implemented Epanet simulation engine and natively integrated MSX library, for full-range hydraulic and water quality network simulation. It takes advantage of Baseform Core's NETWORK and its 2D / 3D network and results visualization.

\section{PRODUCING IAM PLANS IN PRACTICE}

Over the course of the project and subsequently, the AWARE-P methodology as been applied to the development of corporate IAM plans for a number of water and wastewater utilities of various sizes and institutional nature. Four utilities took part in the pilot programme, each with a drinking water case and a wastewater case. These included urban, rural and industrial areas.

At the strategic level, the establishment of the strategies was based on the objectives and targets defined and on a SWOT analysis (strengths, weaknesses, opportunities \& threats) that showed some commonalities between the different utilities, as shown in Table 1. In 2010, the (then) new Portuguese legislation related to quality of service regulation, which includes a formal requirement for IAM plans, was regarded both as an opportunity and as a threat; however, the 19 utilities currently participating in the 2012-2013 national initiative for IAM (www.iniciativaGPI.org) have singled out this aspect exclusively as an opportunity, demonstrating that they feel more comfortable about the application of this legislation with the methodologies and the new tools developed. 
Table 1 - Common aspects of SWOT analysis at four project partner utilities, 2010

\begin{tabular}{|c|c|}
\hline STRENGTHS & WEAKNESSES \\
\hline $\begin{array}{l}\text { - Good information systems on the water supply } \\
\text { infrastructures } \\
\text { - Sufficient information to assess the water supply } \\
\text { systems condition and performance } \\
\text { - Strong competence of human resources } \\
\text { - Relation between information systems and work } \\
\text { orders }\end{array}$ & $\begin{array}{l}\text { - Insufficient information systems on wastewater } \\
\text { infrastructures } \\
\text { - Financial restrictions } \\
\text { - Inadequate tariffs } \\
\text { - Poor structural infrastructure condition } \\
\text { - Poor functional infrastructure performance } \\
\text { - Insufficient historical records } \\
\text { - Inadequate quality of data }\end{array}$ \\
\hline OPPORTUNITIES & THREATS \\
\hline $\begin{array}{l}\text { - Equipment and technologies available to support } \\
\text { IAM } \\
\text { - Portuguese regulation by ERSAR * } \\
\text { - Portuguese legislation related with IAM } \\
\text { - Incentives for sustainable use of energy }\end{array}$ & $\begin{array}{l}\text { - Portuguese legislation and regulation by ERSAR* } \\
\text { (increase in costs) } \\
\text { - Political uncertainties } \\
\text { - Economic crisis and financial restrictions } \\
\text { - Demographic development uncertainties } \\
\text { - Illegal cross connections in wastewater systems }\end{array}$ \\
\hline
\end{tabular}

The SWOT analysis led to the establishment of strategies. Most drinking water utilities considered "Controlling water losses" and "Promoting proactive rehabilitation practices" as key strategies, whereas most wastewater utilities took up "Reducing untreated wastewater discharges" and "Reducing cross connections and infiltration / inflow in wastewater systems". The common strategies of both types of services were "Improving infrastructure information systems" and "Increasing system reliability".

At the tactical level, the various case studies cover a broad variety of situations in terms of:

- Scenarios of evolution (i.e., relevant changes over time in the external context) - the key scenario factors relevant in the analysed cases are related to demand and to the changes in the regulatory system. Uncertainty associated to each scenario was very different from case to case.

- Infrastructural contexts - the systems studied ranged from recently built to old and degraded networks; there is, in general, surplus of flow capacity, except for some wastewater systems due to excessive stormwater affluences associated to cross connections and infiltration; insufficient system reliability was also identified as problem, in several cases.

- Drivers -in two of the cases, the scenarios were the main driver; in all other cases, the infrastructural contexts governed the process.

Several of the utilities took the opportunity to review their IAM tactical plan models, with an emphasis on the tactical objectives and targets, the issues arising from diagnosis, the priority areas chosen and the alternatives selected for each of them, with clear and quantified justification of the decisions made. This global plan also specifies the implementation plan, the financial plan and the procedure for monitoring/review, complemented with O\&M tactics and with other relevant noninfrastructural tactics (e.g., related to information or to accounting and financing management).

The main findings of the group effort include:

- the importance of alignment and coherence between strategic, tactical and operational levels;

- the advantages of a progressive tactical stage where subsystems are prioritized for intervention, before detail plans are devised for each;

- the benefits of systematic diagnosis as a basis to tackle IAM from a level field of a comprehensive set of identified problems and issues, particularly at the tactical stages where the actual intervention solutions are devised.

The tactical planning applied by the utilities followed distinct paths and levels of detail in the analysis. The following section presents one of the cases. 


\section{EXAMPLE OF TACTICAL PLANNING IN A MIDSIZE UTILITY}

The specific case of a drinking water system of a midsize utility is used to illustrate in more detail the path from diagnosis to the development and assessment of intervention alternatives, at the tactical level. Tactical planning was based on the main results of the strategic planning summarised in Table 2. The main strategies identified were: "Perform planned rehabilitation", "Reduce water leakage" and "Promote the efficient use of water".

Table 2 - Strategic objectives and assessment criteria

\begin{tabular}{ll}
\hline Strategic objectives & Criteria \\
\hline 1. Adequacy of the service provided & 1.1 Service accessibility; \\
& 1.2. Quality of service provided to customers \\
2. Sustainability of the service provision & 2.1. Economic sustainability; \\
& 2.2. Infrastructural sustainability; \\
& 2.3. Physical productivity of human resources \\
3. Environmental sustainability: & 3.1. Efficiency of use of environmental resources \\
\hline
\end{tabular}

Based on the strategic planning results, the following tactical IAM objectives were established:

- Increase the system reliability in normal and contingency conditions (see criterion 1.2);

- Ensure economic sustainability (see criterion 2.1);

- Ensure the infrastructural sustainability of the system (see criterion 2.2);

- Decrease water losses (see criterion 3.1).

At a first stage of the tactical planning, the network was divided into trunk main system and subsystems (DMAs, or District Metering Areas). The identification of DMAs with higher priority of intervention was based on the assessment of the selected metrics for all DMAs. Not only the current situation was taken into consideration, but also the response of the existing systems to the predicted evolution of external factors (e.g., demands, regulation, funding opportunities, economics).

DMA 542 was in this high priority group, since it failed to comply with most tactical targets. DMA 542 is a stable and heterogeneous urban area, comprising new and old residential buildings, schools, shops and some commercial areas. It supplies approximately 10,000 people (4,388 contracts) with a network of approximately $12.5 \mathrm{~km}$ of total pipe length, $40 \%$ of which in asbestos cement and the remainder in newer plastic pipes. Water is supplied by gravity from the Amadora Média service tank at elevation $185 \mathrm{~m}$, to the north. The lowest ground elevation in the network is $107 \mathrm{~m}$.

The tactical plan was designed for a 5-year planning horizon (2011-2016). Any envisaged alternative solutions will have to be scheduled over a 5-year period. However, they will be evaluated over a 20-year analysis horizon in order to ensure that the interventions planned are the best compromise both in the medium-term and in a long-term perspective (Alegre et al., 2011). The available investment budget for this DMA allows for the replacement of approximately $1 \mathrm{~km}$ of pipeline per year, for 5 years. Reference assessment timesteps were considered at years $0,1,2,3,4$, $5,10,15$ and 20 . Year 0 is 2011 and year 20 is 2031 .

Since this example involves only alternatives related to physical intervention in the infrastructure, compliance with the above-mentioned tactical IAM objectives was assessed through the following performance, risk and cost metrics:

- Inv: investment cost, which represents the net present value at year 0 of the investments during the 5-year plan.

- IVI: infrastructure value index (IVI) is the ratio between the current value and the replacement value of the infrastructure (Alegre and Covas, 2010); it should ideally be 0.5 . 
- $\mathbf{P}_{\min }$ : minimum pressure under normal operation index, which represents the demand locations that comply with the minimum pressure requirements.

- $\quad \mathbf{P}_{\min }{ }^{*}$ : minimum pressure under contingency conditions index, which represents the demand locations that comply with the required minimum pressure when the normal water source to this DMA fails and an alternative entry point is activated.

- AC: percentage of total pipe length in asbestos cement. Although it does not look like an ordinary performance indicator, this metric was selected as a proxy for system resilience, reliability and ease of maintenance.

- RL: real losses per connection, as defined in IWA performance indicator system.

- UnmetQ: risk of service interruption. This reduced service metric is given by the expected value of unmet demand over 1-year period, as calculated by UNMET. The risk of service interruption associated to a specific pipe depends on the likelihood of its failure and on its consequence on the actual service. This risk is calculated for each pipe as a combination of failure probability, calculated in FAIL, and component importance, calculated in CIMP.

The values of the metrics were further assigned to 3 classes (good, fair and poor) according to the thresholds in Table 3, set by the utility based on the experience of their key personnel.

Table 3 - Multi-criteria reference values

\begin{tabular}{|c|c|c|c|}
\hline & Good (green) & Fair (yellow) & Poor (red) \\
\hline Inv (cost units) & {$[0,350[$} & {$[350,450[$} & {$[450, \infty[$} \\
\hline IVI (-) & ] $0.45,0.55[$ & {$[0.30,0.45[;[0.55,0.70[$} & {$[0,0.30] ;[0.70,1]$} \\
\hline $\mathbf{P}_{\min }(-)$ & {$[3,2[$} & {$[2,1[$} & {$[1,0]$} \\
\hline $\mathbf{P}_{\min } *(-)$ & {$[3,2[$} & {$[2,1[$} & {$[1,0]$} \\
\hline $\mathbf{A C}(\%)$ & {$[0,9[$} & {$[9,15[$} & {$[15,100]$} \\
\hline $\mathbf{R L}\left(1\right.$ connection ${ }^{-1}$ day $\left.^{-1}\right)$ & {$[0,100[$} & {$[100,150[$} & {$[150, \infty[$} \\
\hline UnmentQ (m³/year) & {$[0,20[$} & {$[20,30[$} & {$[30,100]$} \\
\hline
\end{tabular}

Diagnosis of the current situation (year 0) at DMA 542 using the assessment metrics and associated reference allowed the identifications of following problems:

- Reliability of the system: insufficient pressure in normal conditions in some locations; high pipe failure rates; low system resilience of to cope with contingency operation conditions.

- Infrastructural sustainability: poor condition asbestos cement pipes, with high failure rates.

- Water losses: undesirable leakage levels.

Several system-driven solutions and like-for-like replacement solutions were analysed (Marques $e t$ $a l ., 2011$ ) and designed to solve or mitigate the problems identified in the diagnosis. The best of each type and the status quo situation for the case of DMA 542 are presented as follows.

- Alternative A0 (status quo): corresponds to keeping the existing network and the current reactive capital maintenance policy (i.e., repairs after break only).

- Alternative A1 (like-for-like replacement): an IAM project consisting of a prioritized list of pipes to be replaced by the same-diameter HDPE pipes. The prioritized list was developed externally to the AWARE-P software, following a like-for-like replacement strategy, using pipe failure and consequence analysis (as in FAIL/CIMP) and an ELECTRE TRI decisional method, and taking into consideration 3rd-party coordination.

- Alternative A2 (system-driven solution): an IAM project based on an 'ideal' redesign for the network, as if it were built from scratch for the present-day context (rather different from when the current network, designed and constructed in the 1940s). This ideal redesign, developed using AWARE-P's modelling, performance and risk capabilities, is taken as a future target that the utility would try to reach by incrementally changing individual pipes as 
they are replaced, and by making some key layout modifications. It addresses the same pipes targeted in A1, but replacing them with new pipes of optimal diameter, except in Year 5, when it plans a new $625 \mathrm{~m}$-long pipe connecting to a neighbouring sector (to the south), improving reliability of supply in emergency situations.

The assessment of the three alternatives was carried out for the 5-year planning horizon and for a 20-year analysis horizon. Table 4 presents the results of the selected metrics for the three alternatives at year 5. Figure 4 shows snapshots of the 3D view of results (a cube), whose axes are assessment metrics, time and alternatives. The values of the majority of the assessment metrics are constant after year 5, with the exception of IVI and UnmetQ. This is due to the constant demand scenario considered and to the fact the utility assumed negligible O\&M cost variation. Hence, in this case the comparison and selection of alternatives can be centred on the values for year 5 .

Table 4 - Case study: results obtained from the evaluation of three alternatives at year 5 (2016)

\begin{tabular}{cccccccc} 
& \multicolumn{7}{c}{ Assessment metrics } \\
\cline { 2 - 8 } Alternatives & $\begin{array}{c}\text { Inv } \\
\text { (c.u.) }\end{array}$ & $\begin{array}{c}\text { IVI } \\
(-)\end{array}$ & $\begin{array}{c}\mathbf{P}_{\text {min }} \\
(-)\end{array}$ & $\begin{array}{c}\mathbf{P}_{\text {min }} \\
(-)\end{array}$ & $\begin{array}{c}\text { AC } \\
(\%)\end{array}$ & $\begin{array}{c}\text { RL } \\
\left(1 \text { conn }^{-1} \text { day }^{-1}\right)\end{array}$ & $\begin{array}{c}\text { UnmetQ } \\
\left(\mathrm{m}^{3} / \text { year }\right)\end{array}$ \\
\hline A0 & 0 & 0.47 & 2.88 & 0.00 & 37.2 & 116 & 36 \\
A1 & 274 & 0.73 & 2.88 & 0.00 & 1.5 & 52 & 22 \\
A4 & 350 & 0.70 & 2.99 & 2.99 & 8.5 & 54 & 18 \\
\hline
\end{tabular}

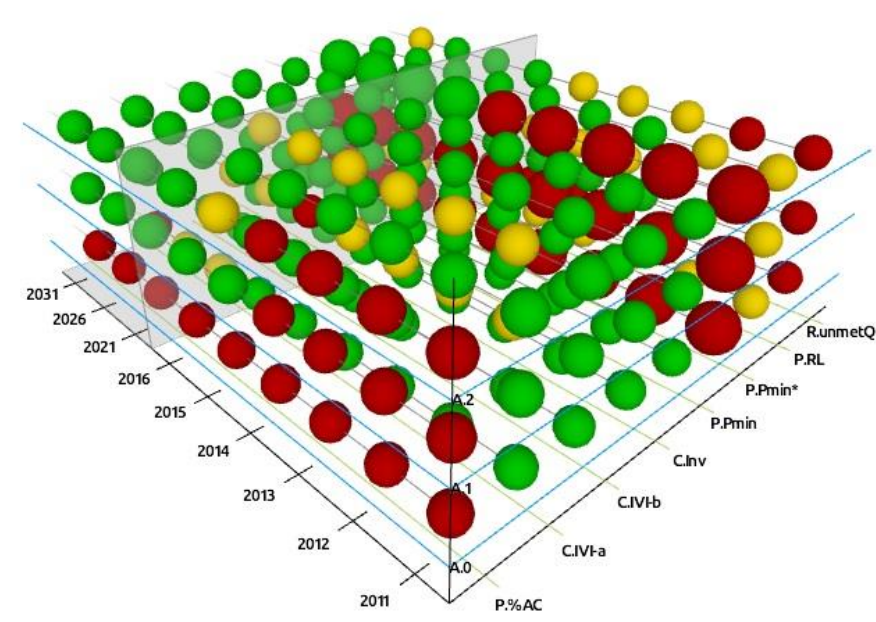

(a) 3D cube with metrics, time and alternative

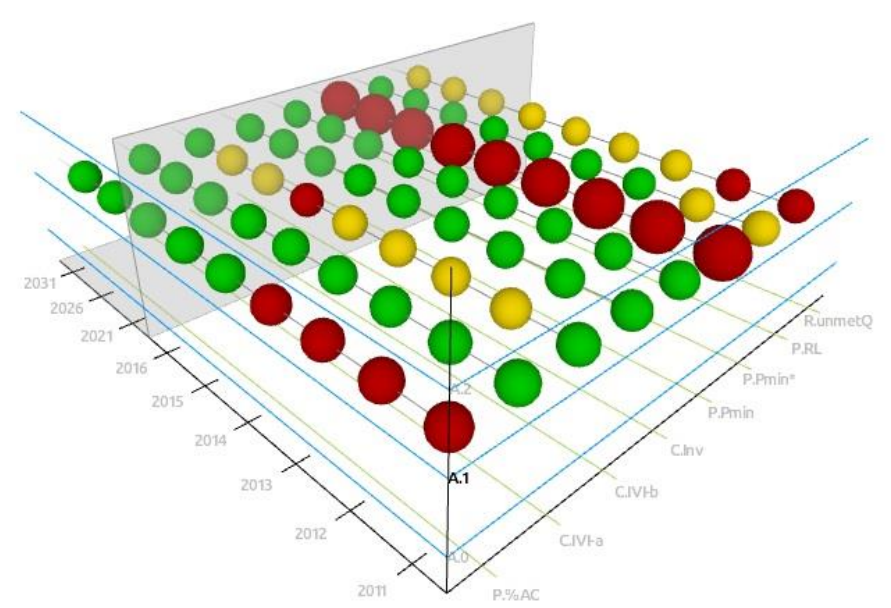

(c) Alternative A1

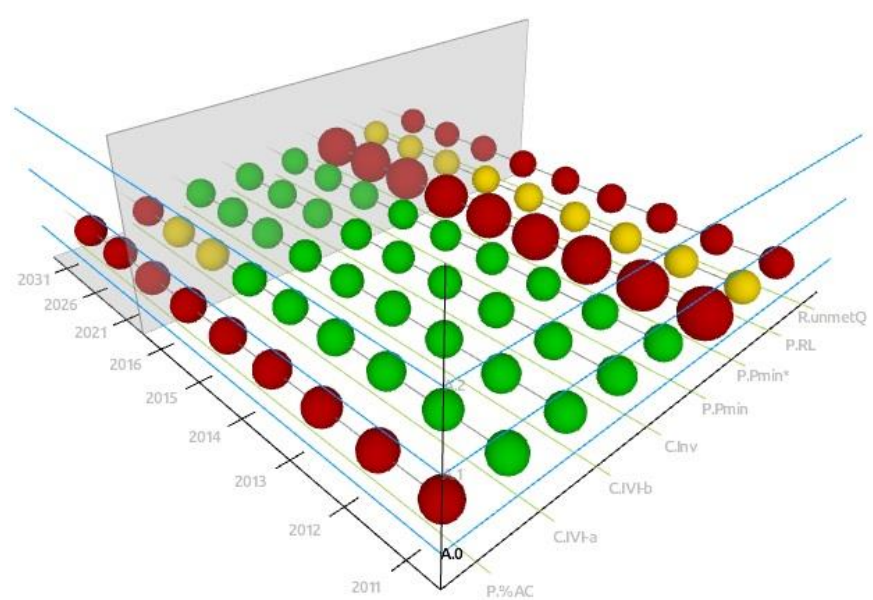

(b) Alternative A0

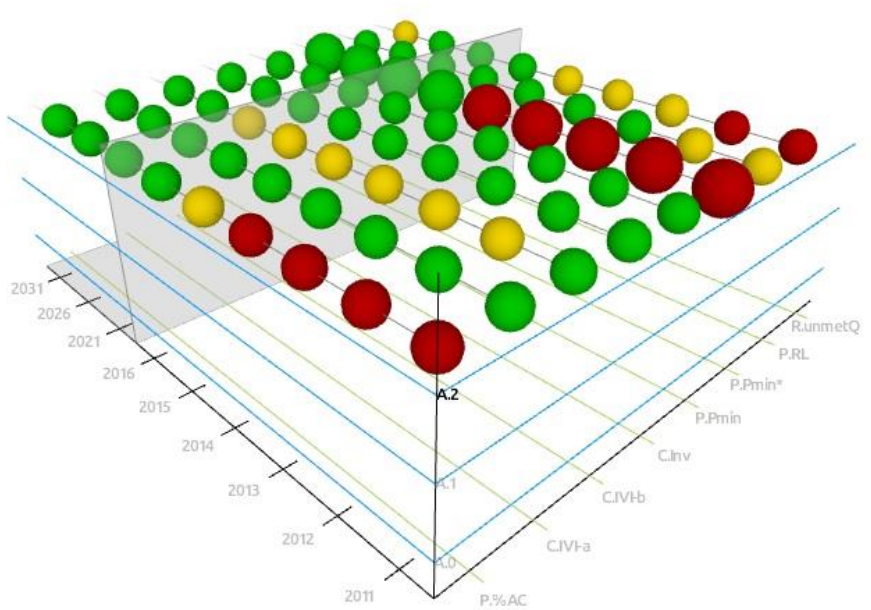

(d) Alternative A2

Figure 4 - Cube of results for the example 
Experience shows that it is often less costly simply to repair pipes and pay for the water lost in leakage than to invest in the rehabilitation of the system. This was confirmed here by looking at A0 at year 5. Afterwards, however, the problems identified in the diagnosis become increasingly evident: poorer network reliability; moderate water losses that tend to intensify due to normal wear.

The results for A1 show that it is generally better than A0 is terms of infrastructural sustainability, water losses and risk (IVI, AC and UnmetQ). Investment is higher than in A0, but within the available budget. However, A1 perpetuates the design deficiencies of the existing (A0) system.

Alternative A2 aims at realistically and progressively bring the existing network to a configuration closer to the ideal configuration. Its resilience is improved when compared to A0 and A1, as it considers the possibility of supplying the network from an alternative source. However, investment costs are higher (250 c.u.) than A1 (274 c.u.). The percentage of asbestos cement pipes is also significantly reduced to $8.5 \%$ when compared with the results obtained for A0 (37\%).

\section{FINAL REMARKS}

The AWARE-P project aims at creating awareness to the need for effective infrastructure asset management, changing current practices, improving technical know-how in the industry and providing guidance tools and software. The objective of this approach is to encourage and assist urban water utilities in implementing a coherent, structured procedure for IAM. The AWARE-P software is an innovative proposal in IAM planning analysis, as it makes available on an advanced technology platform the best tools for visualizing, diagnosing and evaluating any given urban water system, through a portfolio of performance, risk and cost models, at both global and detail levels. The paper summarises the current experience in the application of this approach by several water utilities. There is good evidence that this approach provides a standardised and flexible IAM planning framework that can be successfully used to tackle utility problems.

\section{ACKNOWLEDGEMENTS}

The authors are grateful to the entire AWARE-P project team for their contributions and commitment, as well as to the Financial Mechanism Office of EEA Grants for their support to the project. Very special thanks to the participating utilities - AdP Serviços, S.A., AGS, S.A., Veolia Águas de Mafra and SMAS Oeiras and Amadora - and to the National Regulator, ERSAR.

\section{REFERENCES}

Alegre, H., Covas D., Coelho, S.T., Almeida, M.C., Cardoso, M.A. (2011). Integrated approach for infrastructure asset management of urban water systems. IWA 4th LESAM, Germany.

Brown, R. E., Humphrey, B. G. (2005). Asset management for transmission and distribution. Power and Energy Magazine, IEEE, 3(3,39).

Cardoso, M. A., Santos Silva, M., Coelho, S. T., Almeida, M. C., Covas, D. (2011). Urban water infrastructure asset management - structured approach in four Portuguese water utilities. IWA 4th LESAM, Germany.

Coelho, S. T., Vitorino, D. (2012). A system-centric approach to infrastructure asset management planning. 2012 EWRI WDSA (ASCE), Albuquerque, USA.

Hughes, D. M. (2002). Assessing the future: Water utility infrastructure management. AWWA,USA (644 p.).

INGENIUM, IPWEA (2006). Internat. infrastructure manag. manual, vs 3.0. Assoc. Local Govmt Eng. NZ Inc (INGENIUM) and Inst. Public Works Eng. of Australia (IPWEA), ISBN: 0-473-10685-X (360 p.).

Marques, M. J., Saramago, A. P., Silva, M. H., Paiva, C., Coelho, S., Pina, A., Oliveira, S. C., Leitão, J. P., Coelho, S. T. (2011). Rehabilitation in O\&A: A Practical Approach. IWA $4^{\text {th }}$ LESAM, Germany.

Sægrov, S. ed. (2006). CARE-S - Computer Aided Rehab for Sewer and Stormwater Networks. IWA Publ., ISBN: $1843391155,(140$ p.).

Sneesby, A. (2010). Sustainable infrastructure management program learning environment (SIMPLE). Sustainable Infrastructure and Asset Management Conf., Australian Water Assoc. 23-24 November 2010, Sydney, Australia (CD). 